\title{
Draft of Robotic Workstation for Laser Engraving
}

Frantisek Klimenda (ORCID: 0000-0001-7937-3755), Jan Sterba (ORCID: 0000-0002-2676-3562), Vit Cernohlavek (ORCID: 0000-0001- 6816-1124), Josef Ponikelsky, Petr Maran

Faculty of Mechanical Engineering, J. E. Purkyne University in Usti nad Labem. Pasteurova 3334/7, 40001 Usti nad Labem. Czech Republic. E-mail: Frantisek.klimenda@ujep.cz

The article deals with the design of a robotic workplace for laser engraving. The first part of the article describes the importance of introducing robotics to industry 4.0. Custom solutions work is devoted to the implementation of the six-axis robotic arm UR10. This six-axis robotic arm inserts the designed jig with the semi-finished product into the engraving machine. In the engraving machine, the semi-finished product is engraved on the final product. This saves the operator time to pinpoint the position of the semifinished product inside the engraving machine. The proposed jig is designed to be universal so that the position in the $\boldsymbol{x}$-axis and in the $\boldsymbol{y}$-axis can be precisely defined. At the end of the jig there is a bed for placing the semi-finished product, which can be replaced by another in the case of other dimensions of the semi-finished product. The conclusion is a comparison of time savings in individual steps and overall engraving time savings for one engraved part.

Keywords: Robotic Arm, Laser, Engraving, Marking

\section{Introduction}

The application of robotics in production is a topic not only today, but also the future of industry. Robotics has undergone a long development from singlepurpose manipulators to today's intelligent and collaborative industrial robots. The use of a collaborative robot for cooperation with the operator seems to be the best option guaranteeing a reduction in injuries and an increase in work productivity. Without a robot, the operator must repeatedly perform monotonous operations that adversely affect his physical health and also expose him to laser danger, as the operator must insert the blank directly into the laser station. Today, laser engraving is the most widely used method not only for marking materials, but also for the production of advertising or decorative items. Semi-finished products in industry are marked with a laser for traceability, so a certain type of unique code is created on the material. This code allows the operator to trace back the semi-finished product or the final product in the database. Thanks to the speed, accuracy and high quality of marking and engraving, the laser marking method has no competition on the market. However, just like the method of mechanical engraving, the method of laser engraving has its necessary measures against damage to the health of operators. Laser engraving can be very dangerous for the operator if the safety instructions and elements are not observed. Impact of a high-intensity laser on the skin results in burns. If the laser hits the eye, permanent damage to the operator's vision may be caused. In the workstation with the robot, the robot performs handling work and work potentially dangerous to the health of the operator. The operator still remains at his workplace, with the fact that he handles the material only minimally and rather devotes himself to operating the robot from a safe distance. The design of a suitable solution for a robotic workplace, material handling and safety elements brings time savings, return on investment, increased productivity and safety for operators moving near the laser.

\section{Design of a robotic workplace}

When designing a robotic workplace, it is necessary to proceed from predetermined requirements for the workplace. It is necessary to know the use of work space, but also the technology and equipment that the workplace will have. The design of the workplace is crucial for the production process. Improper arrangement of elements in the workplace can lead to both time and financial losses. These are one of the few reasons why a workplace design should not be underestimated. When introducing new production processes and the associated purchase of new machines (manipulators, robots etc.), a quick return on investment is important. The return could be partially slowed down by inappropriate design of the robotic workplace. Care should also be taken to save jobs. The greater the savings of individual workplaces, the greater the total number of workplaces in one production hall can be in the final. This is also associated with saving money for the otherwise necessary purchase or lease of another production hall.

The design of a robotic workplace for laser engraving was commissioned by KEYENCE as the topic of 
the bachelor's thesis. The aim of the work is an implement a robotic arm into an engraving workplace for engraving small series of advertising products. The company owns an unused robotic arm from the manufacturer ABB. For an existing engraving station, the operator must manually insert and center the engraving blanks into the engraving machine. These operations were time consuming and due to the manual positioning of semi-finished products, each engraved part was original. The main requirement for a new robotic engraving workplace is that the same position of semi-finished products in the chamber of the engraving laser is always ensured. A jig is designed to always ensure the same position of the blank in the chamber of the engraving laser. The jig is placed in the chamber by means of a robotic arm.

A new robotic workplace for laser engraving will be created on the basis of this work. This work serves only as one of the possible models. For the purpose of this work is the design department realized from available resources Laboratory Automation and Robotics Institute of Machinery and Energy Engineering of Faculty of Mechanical Engineering of the J. E. Purkyne University in building laboratories $\mathrm{Za}$ Valcovnou 8. The KEYENCE company lent us the
MD-X1000C Engraving Laser, which they use at the existing manual engraving workplace. The workplace for laser engraving consists of three tables and a laboratory trolley.

- table for engraving laser technology - (Fig. 1) carries equipment exclusively for laser engraving. In the foreground is an engraving box in direct contact with the table. The whole process of laser engraving and marking takes place right inside this engraving box, where the input semi-finished product is inserted. An engraving (writing) head is detachably mounted on this engraving box. The upper surface of the engraving box contains a circular hole which is filled with an engraving head which directs the laser beam. This opening ensures the entry of the laser beam into the engraving box, where the semi-finished product is engraved. Behind the engraving box there is a laser beam control unit and a source.

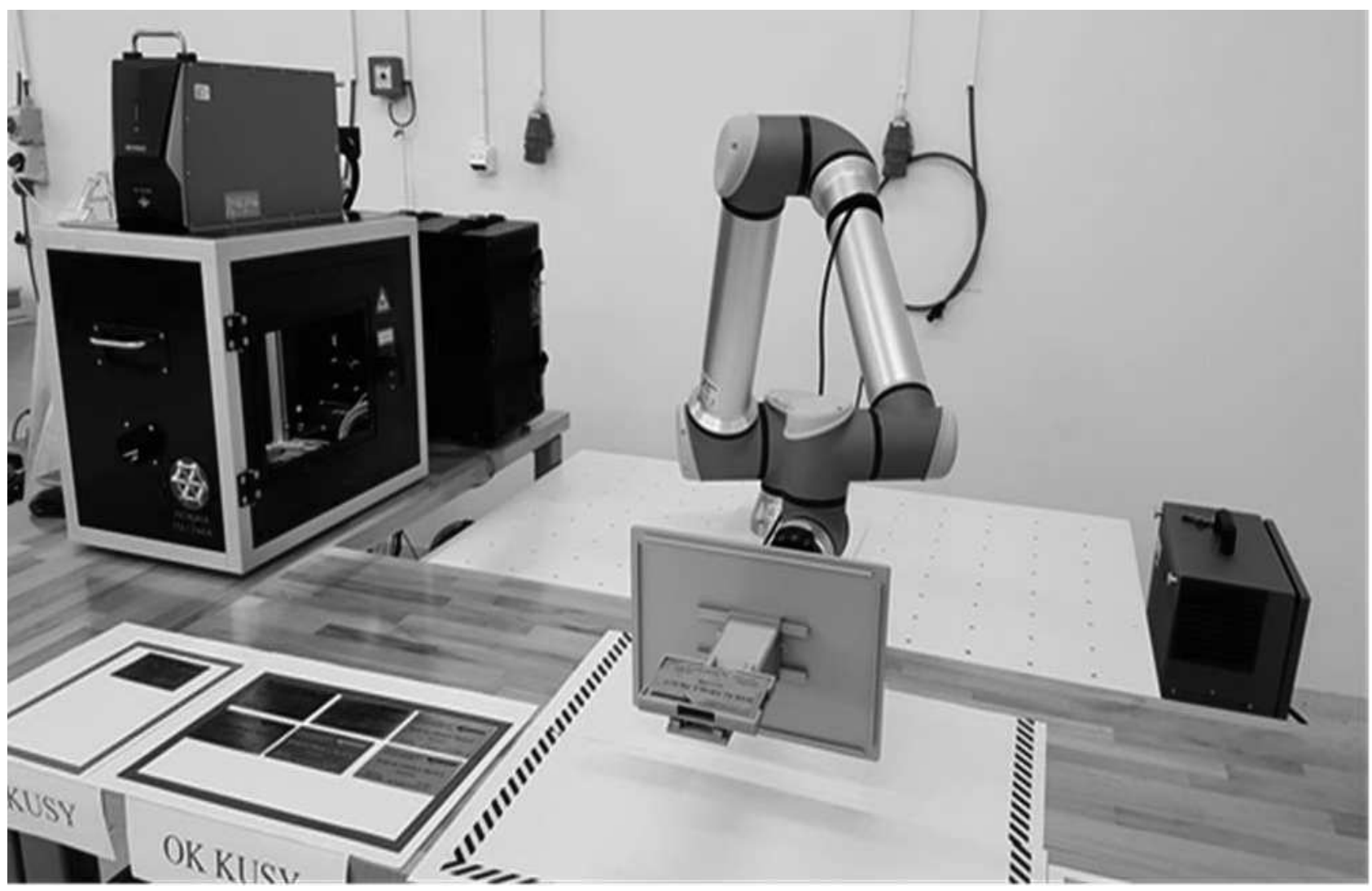

Fig. 1 Designed robotic workplace - robot arm UR10 and engraving equipment

- the operator's table - (Fig. 2 in the middle) serves as the working space of the operator, who handles the semi-finished products here. By this manipulation is meant unloading the semi-finished products from the laboratory trolley, placing the semi-finished products in 
the loading frame for the engraving process and inserting the already engraved finished product into the marked area between $\mathrm{OK}$ or NOK products. The working space of the operator is supplemented by the safety marking of the working space of the robotic arm (it extends into the working space of the operator), the marking of the space for input material and the marking of the space for finished OK and NOK products.

- table for robotic arm - (Fig. 2) is located between the table for engraving laser technology and the operator's table. This table is used to firmly mount the collaborative robotic arm. The robotic arm is thus placed on a sufficiently rigid surface, which prevents inaccuracies in the movement of the robotic arm. At the same time, it defines the working area of the robotic arm, into which no one and nothing should enter during the execution of the program. To the right of the robot table is the control box. The control box provides inputs and outputs from the UR10 collaborative robotic arm, but mainly contains a memory card on which software for the robotic arm and user-created programs is loaded.

- laboratory trolley - (Fig. 2 on the right) contains semi-finished products for engraving, which is located in the semi-enclosed space of the trolley. On the upper storage space is a portable programming case with a PLC and HMI screen for linking the activities of the robotic arm and the laser engraver.

\subsection{MD-X engraving laser}

The MD-X1000C laser (Fig. 3) is a hybrid stationary engraver whose marking laser moves in three axes. The machine is equipped with oscillating technology combining the advantages of YVO4 and fiber lasers. YVO4 lasers (the active medium is yttrium vanadate yttrium vanadium garnet) are characterized by very good marking quality and fiber lasers in turn with high marking speed. The graphic design for engraving was created in the Marking Builder 3 software - see Fig. 4.

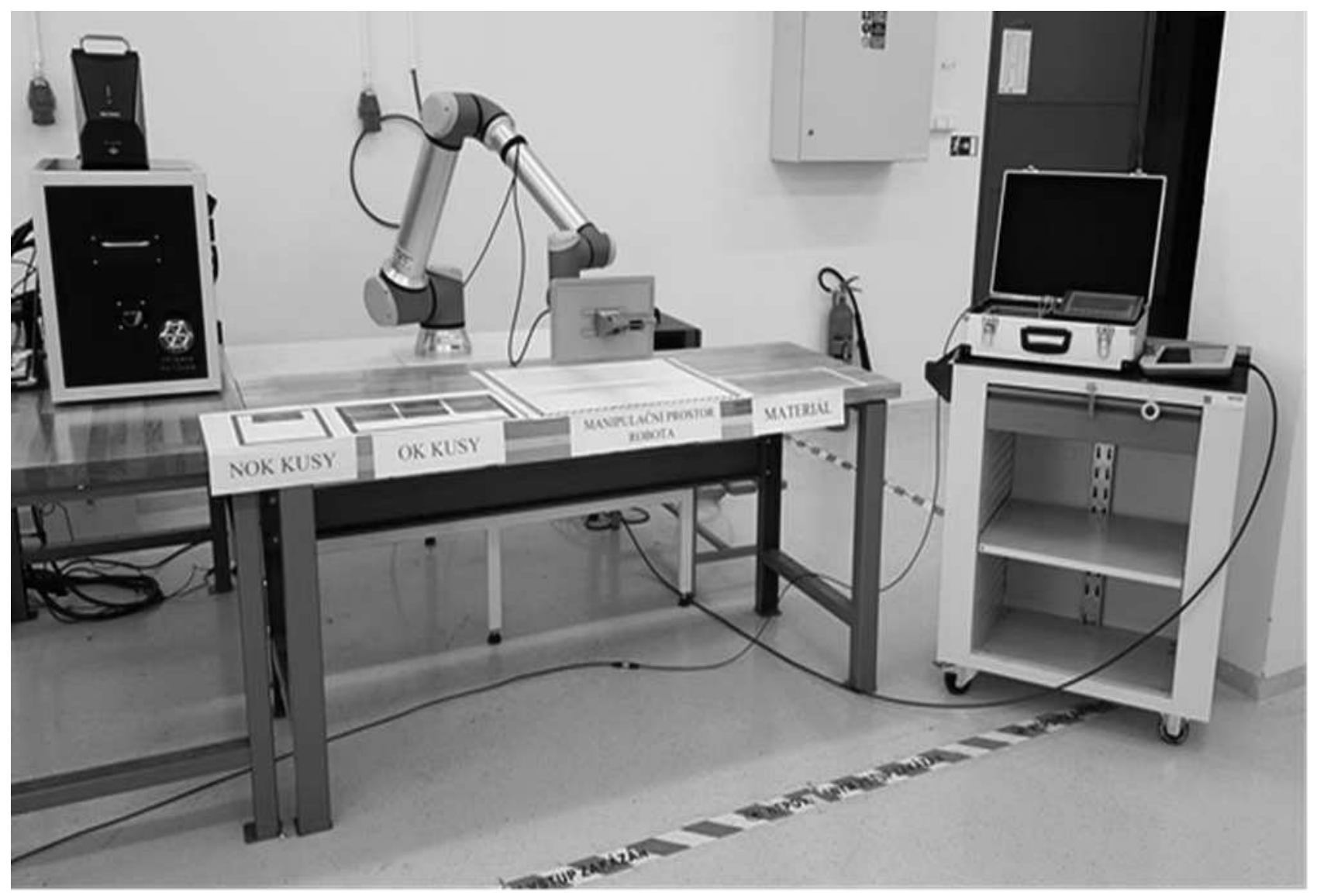

Fig. 2 Designed robotic workplace - complete view 


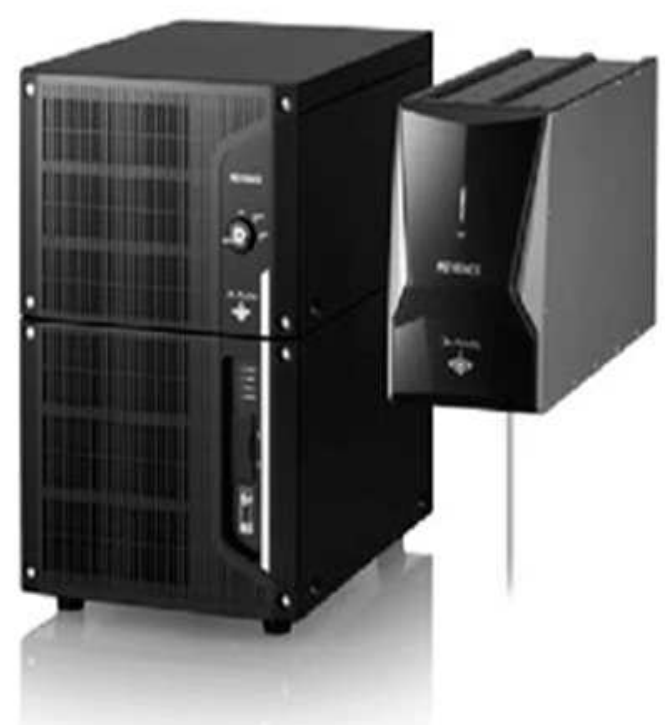

Fig. 3 Engraving laser MD-X1000C

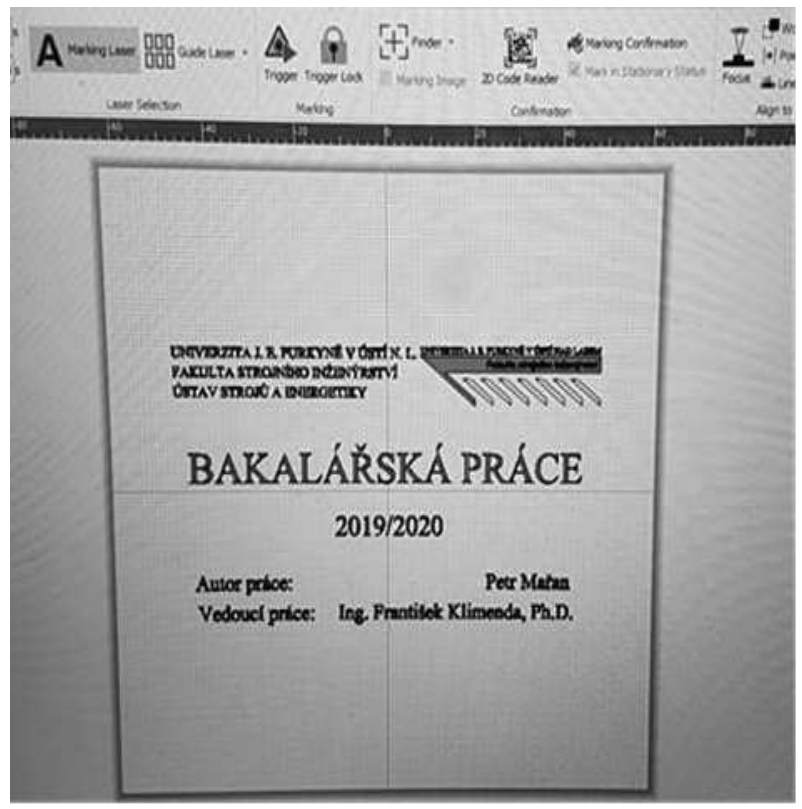

Fig. 4 Graphic design for engraving

\subsection{Design of jig}

The laser beam impinges on the material and engraves it at a distance of $179 \mathrm{~mm}$ from the marking laser head. The laser head allows automatic adjustment of the focal length with a tolerance of $\pm 21 \mathrm{~mm}$ from the height of the semi-finished product for engraving. The jig was designed for precise placement of the semi-finished product in the engraving box and for repeatability of engraving in small series production. The individual parts of the prototype jig were printed using additive technology and then assembled into one unit. During the construction of the jig, sliding dovetails were created on the components, which served to precisely define the position of the material for engraving in the $x$-axis and $y$-axis (Fig. 5).

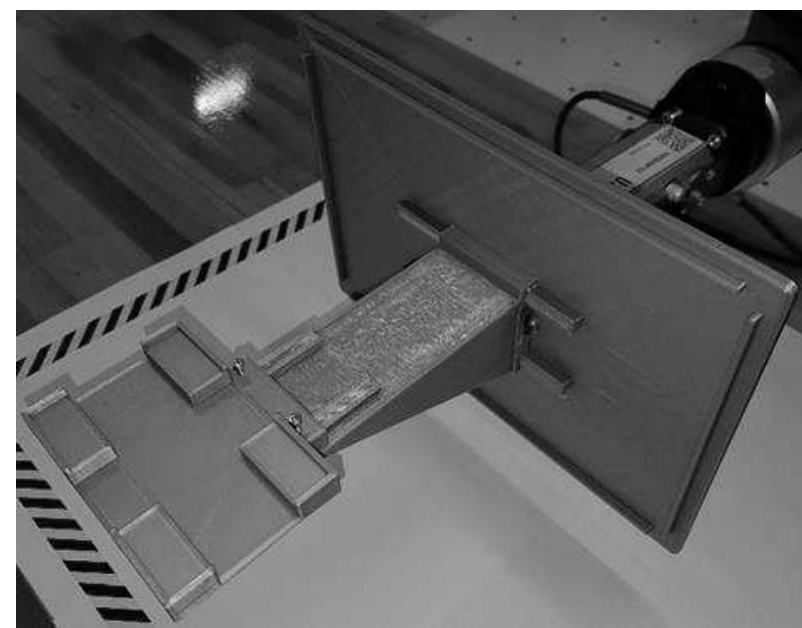

Fig. 5 Jig for the establishment of semi-finished product

\subsection{Six-axis robotic arm UR10}

Unlike humans, the robot never gets tired physically or mentally, the quality of his work is constant. Robot does need proper maintenance to run correctly as it wears out and becomes obsolete. In addition, the robot can work in dusty, wet and noisy environments. A most of robots are used in the automotive industry, where robots are welding, cutting, assembly, painting etc. The robot is also used for packaging and palletizing of products. This involves unloading and loading semi-finished or finished products in the machining centers. They are also used in the area where the exact position of the part is scanned by the camera, the robot grabs it and moves it to a given place, the so-called "pick and place" tasks. In our case it used six-axis robotic arm UR10 - see on Fig. 6.

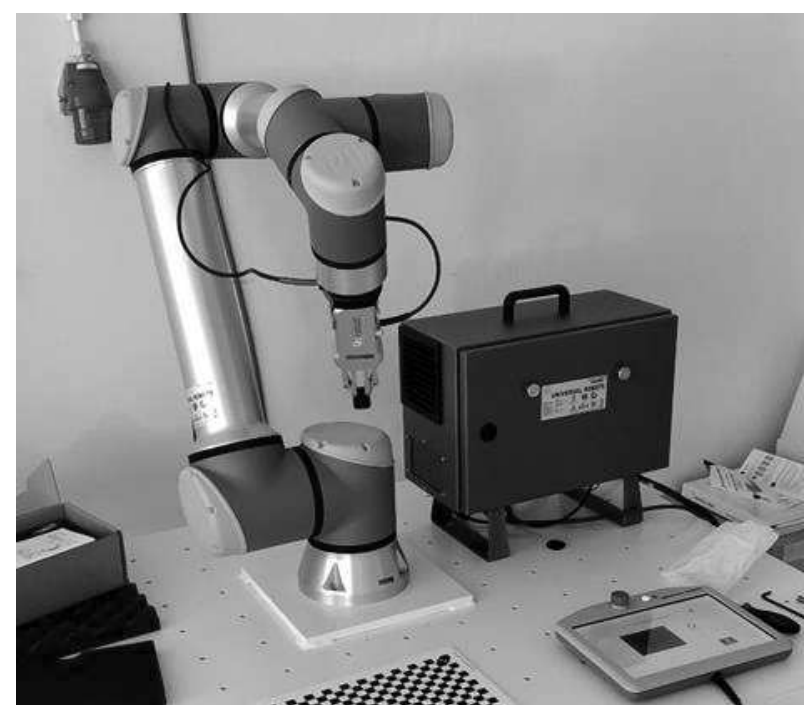

Fig. 6 Six-axis robotic arm UR10

\section{Solution}

A sheet metal with a thickness of $1.5 \mathrm{~mm}$ and dimensions of $70 \times 110 \mathrm{~mm}$ was chosen as the input semi-finished product for engraving.

The type of material was 
- $\quad$ stainless steel (polished and unpolished),

- galvanized carbon steel,

- brass.

The size and types of material were specified by the

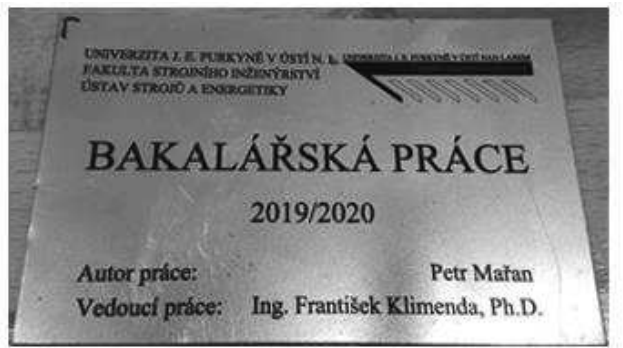

a)

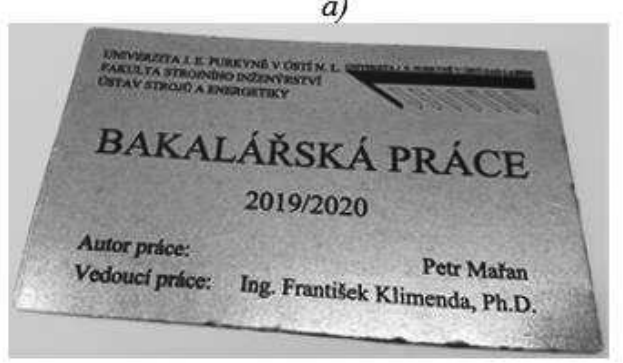

c) contracting authority. Parameters for laser engraving were supplied by the client. Setting laser parameters affect the resulting color after engraved. Fig. 7 shows the results of the colors of the engraved sheets using different laser parameters (Tab. 1). Laser parameters also have an impact on the overall time engraving.

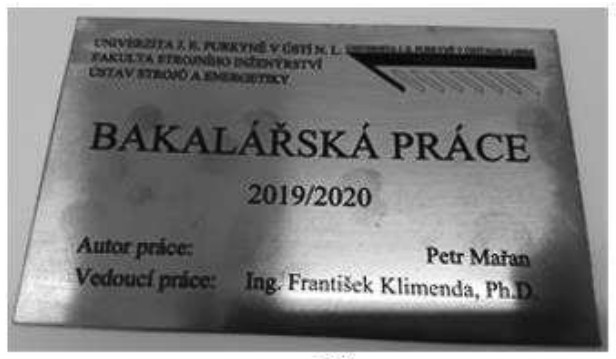

b)

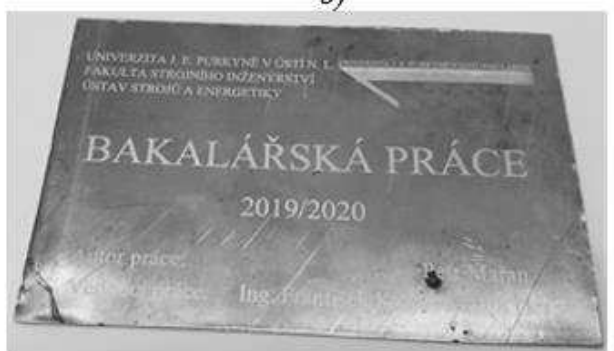

d)

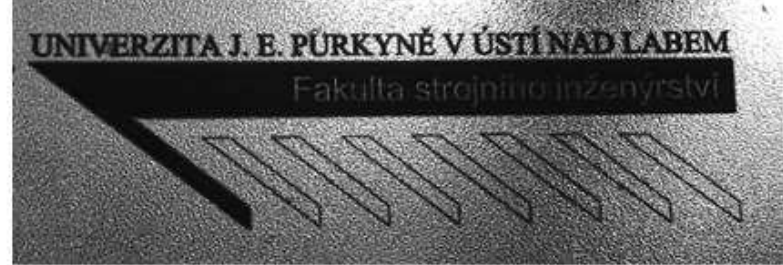

e)

Legend: a) Stainless steel sheet with parameters for the formation of a dark brown color, b) Polished stainless steel sheet with parameters for the formation of black color, c) Galvanized steel sheet with parameters for the formation of dark gray color, d) Brass sheet with parameters for the formation of white color, e) Detail on the contrast between the bright name of the faculty and the dark background

Fig. 7 Examples of colors of engraved plates

Tab. 1 Color depending on the parameters of the engraving laser

\begin{tabular}{|l|c|c|c|c|}
\hline \multirow{2}{*}{\multicolumn{1}{c|}{ Parameters of laser }} & \multicolumn{4}{c|}{ Color } \\
\cline { 2 - 5 } & White & Dark brown & Dark grey & Black \\
\hline Laser Power [\%] & 60 & 80 & 90 & 100 \\
\hline Engraving Speed [mm/s] & 1000 & 100 & 90 & 80 \\
\hline Frequency [kHz] & 80 & 80 & 80 & 80 \\
\hline Repetition [-] & 2 & 1 & 1 & 1 \\
\hline Total engraving time [s] & 81 & 122 & 142 & 159 \\
\hline
\end{tabular}

The condition of the contracting authority was always the same position of the semi-finished product in the chamber of the engraving laser. This requirement has been achieved by means of a jig which is attached to a robotic arm which always ensures the same position in the engraving chamber. By the fact that the operator does not have to manually insert and center the semi-finished products in the engraving chamber, the time saving of the whole engraving process was obtained and the claims of defective products were eliminated. This makes it possible to accept larger orders or more smaller orders at once. By processing more orders, a higher profit is obtained, which covers the costs associated with the maintenance of the robotic arm and the energy for the operation of the robotic arm.

An integral part in the design of any workplaces is primarily to ensure operator safety. In this case, it 
would not be fenced workplace safety fencing as laboratory robotic arm UR10 is a collaborative. It stops when hitting an obstacle. In a real workplace, where the $\mathrm{ABB}$ robotic arm will be used, the robot's working space must be fenced a safety mesh to prevent contact with the operator. The ABB robotic arm is not collaborative. The working space of the operator, where the semi-finished products are loaded into the jig mounted on the robotic arm, is secured by an optical gate, which is closed at the time of manipulation of the robotic arm and engraving. The operator would insert his hands into the optical gate, the power supply would be interrupted, and the robotic arm and engraving would be interrupted. The optical gate turns off when the robotic arm is in the rest position so that the operator can insert the semi-finished products or remove the finis products. Another measure is an optical sensor within the chamber laser engraving. This sensor senses when a jig with semi-finished product is inserted. If the laser beam is interrupted during engraving, the engraving process will be interrupted. The door remains closed during engraving. If the door opened, this sensor would interrupt the engraving again. Tab. 2 shows the times of individual operations of the whole engraving process. The original times of the individual operations were delivered from the contracting authority. These are average times. The times at the robotic workplace were measured in laboratory conditions. These times will be slightly different in a real robotic workplace. Again, this is the average of several measured times at individual workplaces.

Tab. 2 Comparison of time intensity of individual operations at the original and robotic workplace

\begin{tabular}{|l|c|c|}
\hline \multirow{2}{*}{ Work Operations } & \multicolumn{2}{|c|}{ Time [s] } \\
\cline { 2 - 3 } & 5 & Original \\
\hline $\begin{array}{l}\text { Inserting the semi-finished product into the engraving } \\
\text { box }\end{array}$ & 48 & 0 \\
\hline $\begin{array}{l}\text { Adjusting the correct position of the material for en- } \\
\text { graving }\end{array}$ & 142 & 142 \\
\hline Engraving process & 7 & 10 \\
\hline $\begin{array}{l}\text { Remove the product from the engraving box and place } \\
\text { it between the finished pieces }\end{array}$ & 202 & 160 \\
\hline Total time required to produce one product & & 8 \\
\hline
\end{tabular}

The operator would thus produce 168 finished products in an eight-hour shift (with a half-hour break) while working at a robotic workplace. At the original workplace, the operator would produce only 133 finished products under the same time conditions. The difference during one eight-hour shift at a robotic and non-robotic workplace is 35 pieces of finished products.

\section{Conclusion}

The article deals with the design of a robotic workplace for laser engraving. The introduction of the article describes the reason for the introduction of robotics and engraving into production. The next part of the article is devoted to the design of a robotic workplace, which describes the layout of individual machines in the workplace. The robotic workstation for laser engraving has a six-axis robotic arm UR10 and an engraving laser MD-X1000C. A universal jig has been designed for the precise placement of a semi-finished product for engraving in an engraving box and for the repeatability of engraving. The next step of the solution was the selection of suitable parameters for the engraving process itself. These selected parameters affected the color of the engraved texture in the finished product. At the conclusion of the article is the overall evaluation in terms of time savings on individual engraving operations and the total time savings for engraving one piece of product. Using robotic laser engraving workstations, the time saved to produce one piece of product was 42 seconds. A total of 35 more products will be produced using robotic laser engraving workstations.

\section{Acknowledgement}

The article was created with the support of the Student Grant Agency UJEP-SGS-2020-48-001-2J. E. Purkyne University in Usti nad Labem.

\section{References}

[1] KOLÍBAL, Z. a kolektiv (2016). Roboty a robotizované výrobni technologie. 1. vydání. Brno: VURIUM, 800 s. ISBN 978-80-214-4828-5.

[2] OPLATEK, F., LUNER, M., OSOBA, J., SVOBODA, K., ŠMEJKAL, L. (2000). Automatizace a automatizační technika 4. 1. vydání. Praha: Computer Press. 172 s. ISBN 80-7226249-1.

[3] BOKR, J., JÁNEŠ, Vl. (1999). Logické systémy. 1. vydání. Praha: Vydavatelství ČVUT. 365 s. ISBN 80-01-01992-6.

[4] BLATNICKY, M., DIZO, J., KURCIK, P., BLATNICKA, M. (2018) Dimensional Calculation of Automatic Soldering Station Chain 
Conveyor's Electric Motor. Manufacturing Technology. Vol. 18, No.2, pp. 194-200, UJEP in Usti nad Labem, ISSN 1213-2489.

[5] PALASCAKOVA, D., DEMEC, P. (2016) Measurement Precision KUKA Robots Move at a Defined Distance and Proposal for a Robotized Workplace to Support the Learning Process. Manufacturing Tecbnology. Vol. 16, No.6, pp. 1344-1350, UJEP in Usti nad Labem, ISSN 1213-2489.

[6] KURIC, I., BULEJ, V., SAGA, M., POKORNY, P. (2017). Development of simulation software for mobile robot path planning within multilayer map system based on metric and topological maps. In: International journal of advanced robotic systems. ISSN 1729-8814. - Vol. 14 , iss. 6, 2017. online, $14 \mathrm{p}$.

[7] KUNDERA, M., CISAR, M., KURIC, I. (2019). Modification of Clamping System Designated for Automatic Workpiece Exchange. Manufacturing Technology. Vol. 19, No.3, pp. 414418, UJEP in Usti nad Labem, ISSN 12132489.

[8] MAŘAN, P. (2020). Návrh technického řešení robotického pracoviště pro laserové gravírování. Ústí nad Labem, 61 s. Bakalárská práce. Univerzita J. E. Purkyně v Ústí nad Labem, Fakulta strojního inženýrství, Ústav strojů a energetiky. Vedoucí práce Ing. František Klimenda, Ph.D. 